\title{
Meningoencefalite e polioencefalomalacia causadas por Herpesvírus bovino-5 no Estado do Pará1
}

\author{
Gabriela Riet-Correa ${ }^{2 *}$, Marcos Dutra Duarte ${ }^{2}$, José Diomedes Barbosa², Carlos \\ Magno Chaves Oliveira ${ }^{2}$, Valíria Duarte Cerqueira ${ }^{2}$, Marilene de Farias Brito $^{3}$ e \\ Franklin Riet-Correa ${ }^{4}$
}

\begin{abstract}
Riet-Correa G., Duarte M.D., Barbosa J.D., Oliveira C.M.C., Cerqueira V.D., Brito M.F. \& Riet-Correa F. 2006. [Meningoencephalitis and polioencephalomalacia caused by Bovine herpesvirus-5 in the state of Pará, northern Brazil.] Meningoencefalite e polioencefalomalacia causadas por Herpesvírus bovino-5 no Estado do Pará. Pesquisa Veterinária Brasileira 26(1):44-46. Central de Diagnóstico Veterinário, Universidade Federal do Pará, Maximino Porpino 1000, Castanhal, PA 68740-080, Brazil. E-mail: griet@ufpa.br

Four outbreaks of meningoencephalitis in 1 to 2 years old cattle caused by Bovine herpesvirus5 are reported in four municipalities in the state of Pará, northern Brazil. In three outbreaks only one animal was affected, in another 3 cattle were affected. Main clinical signs were incoordination, dullness, blindness, recumbence, and opisthotonus. Death occurred after a clinical manifestation period of 3-4 days. Softening and yellowish areas were observed grossly in the cerebral cortex. The histology revealed poliencephalomalacia in the cerebral cortex, thalamus and basal nuclei, and non suppurative encephalitis and meningitis, and eosinophilic intranuclear inclusion bodies in astrocytes. The diagnosis was based on the typical microscopic lesions.
\end{abstract}

INDEX TERMS: Meningoencephalitis, polioencephalomalacia, bovine herpesvirus-5, cattle.

RESUMO.- $O$ presente trabalho relata quatro casos de meningoencefalite por BHV-5 em quatro municípios no estado do Pará afetando bovinos de 1-2 anos, criados extensivamente. Três casos ocorreram de forma isolada e em um caso foram atingidos 3 animais do rebanho. Os principais sinais clínicos observados foram incoordenação, depressão acentuada, cegueira, decúbito lateral, opistótono e morte. 0 curso clínico foi de 3-4 dias. Macroscopicamente observaram-se áreas amolecidas, amareladas e cavitações no córtex cerebral. Microscopicamente observaram-se poliencefalomalacia no córtex cerebral, tálamo e núcleos da base, encefalite e meningite não supurativa e corpúsculos de inclusão intranucleares eosinofílicos em astrócitos. O diagnóstico foi realizado com base nos achados histológicos característicos.

\footnotetext{
${ }^{1}$ Recebido em 18 de outubro de 2005.

Aceito para publicação em 31 de outubro de 2005

${ }^{2}$ Central de Diagnóstico Veterinário, Curso de Medicina Veterinária, Campus de Castanhal, Universidade Federal do Pará, Av. Maximino Porpino da Silva 1000, Castanhal, PA 68740-080. *Autor para correspondência. Email: griet@ufpa.br.

${ }^{3}$ Convênio "Projeto Sanidade Animal Embrapa/Universidade Federal Rural do Rio de Janeiro (UFRRJ)", Seropédica, RJ 23890-000.

${ }^{4}$ Centro de Saúde e Tecnologia Rural, Universidade Federal de Campina Grande, Campus de Patos, Jatobá, Patos, PB 58700-000.
}

TERMOS DE INDEXAÇÃO: Meningoencefalite, polioencefalomalacia, Herpesvírus bovino-5, bovinos.

\section{INTRODUÇÃO}

O Herpesvírus bovino-5 (BHV-5) é um alfaherpesvírus que causa meningoencefalite em bovinos. No Brasil, a doença afeta mais frequientemente bovinos jovens, de 6-7 meses até 3 anos de idade (Riet Correa et al. 1989, Salvador et al. 1998, Colodel et al. 2002, Gomes et al. 2002, Elias et al. 2004). No entanto, surtos têm sido observados em bezerros de até 3 meses (Riet-Correa et al. 1989, Weiblen et al. 1989, Elias et al. 2004) e bovinos adultos de até 6 anos (Salvador et al. 1998, Colodel et al. 2002, Elias et al. 2004). A meningoencefalite por BHV-5 tem sido descrita no Rio Grande do Sul (Riet-Correa et al. 1989, 1996, Weiblen et al. 1989, Schild et al. 1994, Elias et al. 2004), Mato Grosso do Sul (Salvador et al. 1998), São Paulo (Salvador et al. 1998), Paraná (Halfen \& Vidor 2000), Mato Grosso (Colodel et al. 2002), Rio de Janeiro e Minas Gerais (Gomes et al. 2002).

A doença ocorre, geralmente, de forma esporádica, ou em surtos com uma morbidade de 0,05-30\% e letalidade de 75-100 $\%$. Não apresenta caráter sazonal, atingindo principalmente animais criados em regime extensivo em pastagens e raramente bovinos confinados (Riet-Correa et al. 1989, Riet-Correa \& Schild 1995, Colodel et al. 2002, Gomes et al. 2002, Elias et al. 2004). 
Clinicamente, os animais apresentam sinais nervosos como depressão profunda, cegueira, pressão da cabeça contra objetos, movimentos involuntários, nistagmo, opistótono e andar cambaleante, morrendo em 4-14 dias. À necropsia podem se observar áreas amareladas ou acinzentadas e amolecidas no córtex cerebral. Microscopicamente observam-se meningite e encefalite não supurativa e necrose na substância cinzenta do córtex. Podem ser encontradas inclusões virais eosinofílicas intranucleares em astrócitos ou neurônios (Halfen \& Vidor 2000).

0 presente trabalho tem por objetivo relatar 4 casos de meningoencefalite por Herpesvírus bovino-5 diagnosticados no Estado do Pará nos anos de 2000-2004.

\section{MATERIAL E MÉTODOS}

Os dados referentes à epidemiologia e aos sinais clínicos foram obtidos em visitas as propriedades onde ocorreu a doença. Foram necropsiados quatro animais, sendo coletado encéfalo e fragmentos dos órgãos das cavidades abdominal e torácica. $\mathrm{O}$ material coletado foi fixado em formol a $20 \%$ e processado rotineiramente para exame histopatológico. Em um dos bovinos (FC 263), após a fixação do encéfalo, foram realizados cortes transversais seriados do mesmo, coletando-se fragmentos ao nível de córtex parietal, temporal, occipital e frontal, cápsula interna e núcleos da base, tálamo, mesencéfalo à altura do colículo rostral e do colículo caudal, pedúnculos cerebelares, cerebelo, ponte, medula oblonga e medula cervical. Nos demais bovinos (FC201-SAP29320, FC361-SAP30506, FC363-SAP30507) foram processados somente cortes a nível de córtex cerebral.

\section{RESULTADOS}

A doença foi observada nos municípios de Nova Timboteua, Terra Alta, Castanhal e Tome-Açú, nos anos de 2000-2004. Foram afetados animais da raça nelore e mestiços, com idade de 1-2 anos, criados extensivamente. Três casos ocorreram de forma isolada e em um caso foram atingidos 3 animais do rebanho. Os

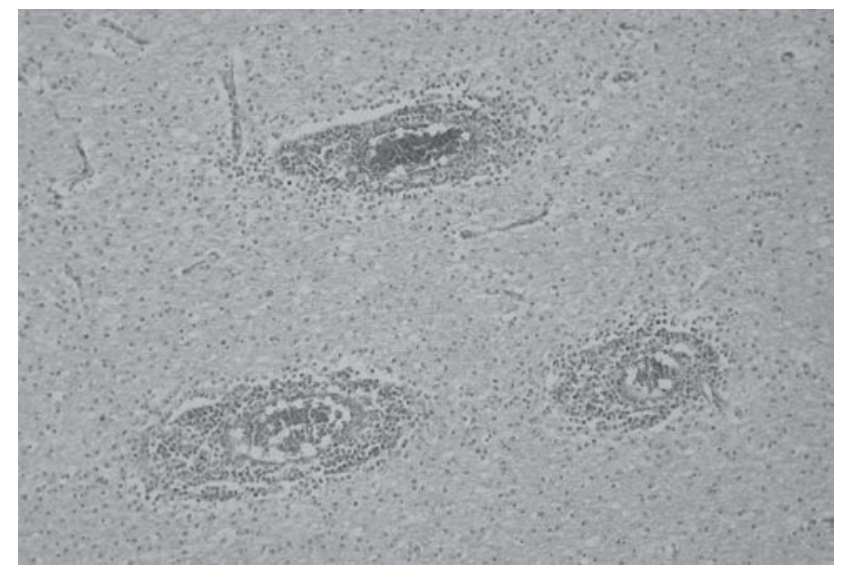

Fig.1. Substância branca subcortical com denso acúmulo perivascular de linfocitos, células mononucleares indiferenciadas, plasmócitos, poucos macrófagos e alguns neutrófilos. Também gliose difusa e hiperplasia do endotelio vascular (Bovino 4, com diagnóstico de meningo-encephalite por Herpesvírus bovino-5). HE, obj 10. casos ocorreram nos meses de novembro (2 bovinos), março e agosto. Os sinais clínicos observados foram incoordenação, depressão acentuada, cegueira, seguido de decúbito lateral, opistótono e morte. 0 curso clínico variou de 3-4 dias. À necropsia não foram observadas alterações significativas. Ao cortar o encéfalo, após a fixação em formol, observaram-se, em todos os casos, áreas amolecidas e amareladas e cavitações no córtex cerebral. No encéfalo do Bovino 4 observaram-se, microscopicamente, no córtex cerebral, substância branca subcortical, tálamo e núcleos da base densos acúmulos perivasculares de linfocitos, células mononucleares indiferenciadas, plasmócitos, poucos macrófagos e alguns neutrófilos (Fig.1). Hiperplasia do endotelio vascular e gliose foram também observadas. No córtex cerebral havia, ainda, áreas extensas de malacia, com substituição do tecido nervoso por células Gitter, e meningite não supurativa (Fig.2). Áreas de malacia, caracterizadas por vacuolização da neurópila e presença de numerosos neurônios eosinofí-

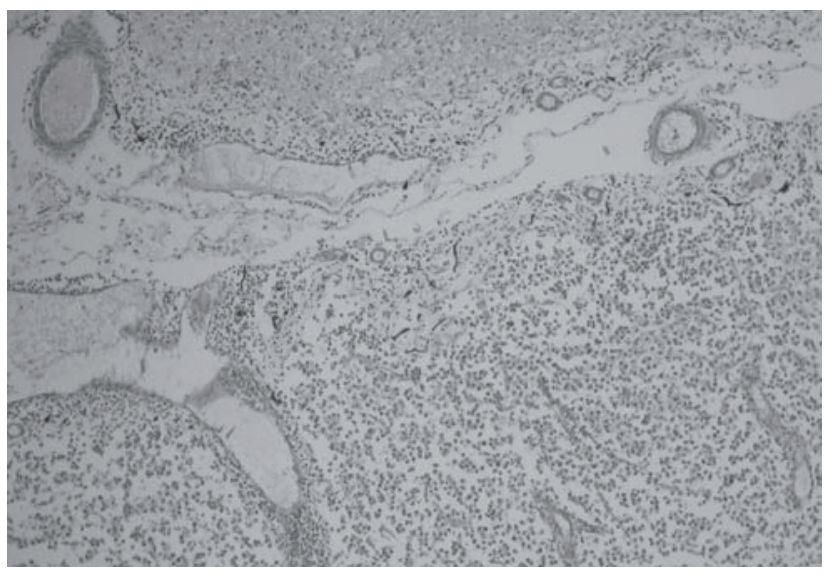

Fig.2. Córtex cerebral apresentando severa malacia com substituição do tecido nervoso por células Gitter, hiperplasia do endotelio vascular e meningite linfocitária (Bovino 4). HE, obj 20.

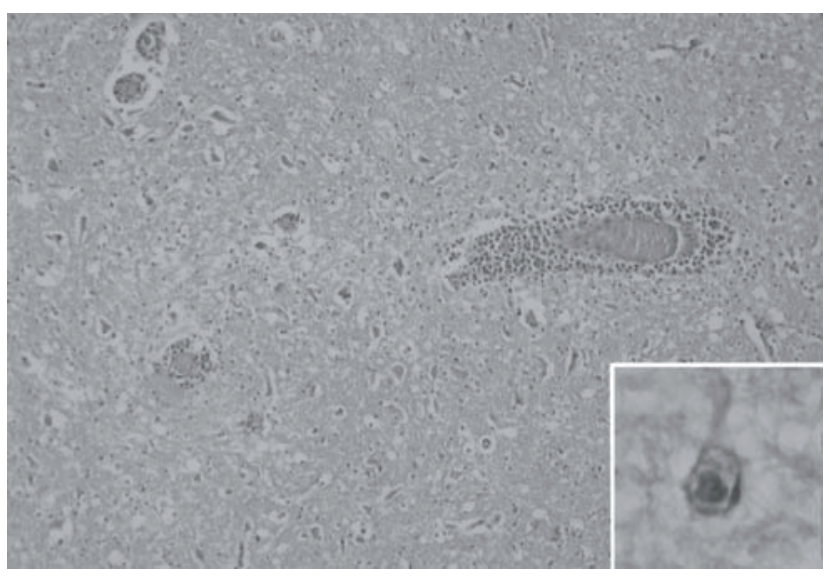

Fig.3. Tálamo com área de malacia, caraterizada por vacuolização da neurópila e presença de numerosos neurônios eosinofílicos, e manguitos perivasculares. $\mathrm{HE}$, obj. 10. Inserido: astrócito com corpúsculo de inclusão intranuclear eosinofílico (Bovino 4). HE, obj 20. 
licos, foram observadas no tálamo (Fig.3) e núcleos da base. Havia corpúsculos de inclusões intranucleares eosinofílicas em astrócitos (Fig.3, inserido). Lesões inflamatórias semelhantes ás mencionadas anteriormente, porém menos severas, foram observadas no mesencéfalo, ponte e medula oblonga. No cerebelo e medula cervical não havia lesões histológicas. Nos demais animais observaram-se, no córtex cerebral, encefalite não supurativa, gliose multifocal, hiperplasia endotelial, áreas de malacia, meningite não supurativa e corpúsculos de inclusão eosinofílicos intranucleares em astrócitos.

\section{DISCUSSÃO}

O diagnóstico de meningoencefalite por BHV-5 foi realizado com base nos achados histológicos característicos: encefalite e meningite não supurativa, polioencefalomalacia e corpúsculos de inclusão eosinofílicos em astrócitos (Halfen \& Vidor 2000).

As lesões histológicas observadas são semelhantes às descritas anteriormente (Riet-Correa et al. 1989, 1996, Salvador et al. 1998, Colodel et al. 2002, Elias et al. 2004); no entanto, chama atenção a presença de áreas de malacia no tálamo e núcleos da base. Estas lesões, denominadas lesões profundas, foram descritas anteriormente por Elias et al. (2004) na meningoencefalite por BHV-5. Lesões profundas de malacia, principalmente nos núcleos da base, tálamo e colículos rostral e caudal são observados em casos espontâneos e experimentais de poliencefalomalacia (PEM) (Tanwar et al. 1993, David 2002). As lesões profundas de malacia nestes casos de infecção por BHV-5 sugerem a possibilidade de que a encefalite seja secundária a lesões prévias de PEM. A mesma possibilidade é mencionada por Elias et al. (2004) em casos de meningoencefalite por BHV-5 no Rio Grande do Sul. Em um trabalho experimental foi demonstrado que animais que tinham sido inoculados anteriormente com BHV-5 desenvolviam meningoencefalite após a indução de polioencefalomalacia mediante a administração de amprólio ou sulfato de sódio (David 2002). Nesses experimentos, um bovino que desenvolveu encefalite após a inoculação do vírus, sem indução de PEM, não apresentou lesões profundas, enquanto que dois dos três animais que desenvolveram, simultaneamente, PEM e meningoencefalite por BHV-5 apresentaram lesões profundas (David 2002). No entanto não pode ser descartada a possibilidade de que as lesões profundas de PEM sejam causadas por algumas cepas de BHV-5. A PEM tem sido diagnosticada em diversos municípios do estado do Pará (Barbosa 2003).

A meningoencefalite por HVB-5 ocorre em vários estados do Brasil (Riet-Correa et al. 1989, 1996, Weiblen et al. 1989, Salvador et al. 1998, Colodel et al. 2002, Gomes et al. 2002, Elias et al. 2004). Apesar da aparente baixa prevalência da enfermidade, apenas quatro casos em um período de 4 anos, é provável que a mesma seja mais freqüiente e que muitos surtos não sejam diagnosticados, especialmente em se tratando de casos isolados, em condições extensivas de criação. Em outras regiões do País ocor- rem casos esporádicos ou surtos com morbidade de até $30 \%$ (Halfen \& Vidor 2000).

Embora sua ocorrência seja, aparentemente, esporádica, o diagnóstico correto da encefalite por BHV-5 é importante, visto a importância do diagnóstico diferencial com a raiva, doença freqüiente na região Norte, e com outras enfermidades que cursam com sintomatologia nervosa semelhante, especialmente a PEM. É necessário estabelecer uma rotina de diagnóstico que permita determinar as enfermidades que afetam o sistema nervoso de bovinos no Estado.

\section{REFERÊNCIAS}

Barbosa J. D. 2003. Comunicação pessoal (Escola de Medicina Veterinária, Campus Castanhal, Universidade Federal do Pará).

Colodel M. E., Nakazato L., Weiblen R., Mello R. M., Silva R. P., Souza M. A., Oliveira J. A. \& Caron L. 2002. Meningoencefalite necrosante em bovinos causada por herpesvírus bovino no estado de Mato Grosso, Brasil. Ciência Rural, Santa Maria, 32 (2):293-298

David N.P. 2002. Associação de meningoencefalite por Herpesvírus-bovino tipo 5 e polioencefalomalacia. Tese de Mestrado, Programa de Pósgraduação em Veterinária, Universidade Federal de Pelotas. 55p.

Elias F., Schild A.L. \& Riet-Correa F. 2004. Meningoencefalite e encefalomalacia por Herpes vírus bovino-5 (BHV-5): distribuição das lesões no sistema nervoso central de bovinos naturalmente infectados Pesq. Vet. Bras. 24 (3):123-131.

Gomes L.I., Rocha M.A., Costa E. A., Lobato Z.I.P., Mendes L.C.N., Borges A.S., Leite R. C. \& Barbosa-Stancioli E.F. 2002. Detecção de herpesvírus bovino-5 (BoHV-5) em bovinos do sudeste brasileiro. Arq. Bras. Med. Vet. Zootec. 54 (2):217-220.

Halfen D.C. \& Vidor T. 2000. Infecções por Herpesvírus bovino-1 e Herpesvírus bovino-5, p.97-107. In: Riet-Correa F., Schild A.L., Mendez M.C., Lemos R.R.A (ed.) Doenças de Ruminantes e Eqüinos. Vol.1. 2a ed. Varela Editora e Livraria, São Paulo.

Riet-Correa F., Vidor T., Schild A.L. \& Méndez M.C. 1989. Meningoencefalite e necrose do córtex cerebral em bovinos causadas por Herpes Vírus Bovino-1. Pesq. Vet. Bras. 9: 13-16.

Riet-Correa F., Moojen V., Roehe P.M. \& Weiblen R. 1996. Viroses confundíveis com febre aftosa: revisão bibliográfica. Ciência Rural, Santa Maria, 26:323-332.

Riet-Correa F. \& Schild A.L. 1995. Doenças diagnosticadas pelo Laboratório Regional de Diagnóstico no ano de 1994 e comentários sobre algumas doenças. Boletim do Laboratório Regional de Diagnostico no.15, Pelotas. 46p.

Salvador S.C., Lemos R.A.A., Riet-Correa F., Roehe P.M. \& Osorio A.L.A.R. 1998. Meningoencefalite causada por herpesvírus bovino-5 no Mato Grosso do Sul e São Paulo. Pesq. Vet. Bras. 18:76-83.

Schild A.L., Riet-Correa F., Pereira D.B., Ladeira R., Raffi M.B., Andrade G.B. \& Schuch L.F. 1994. Doenças diagnosticadas pelo Laboratório Regional de Diagnóstico no ano de 1993 e comentários sobre algumas doenças. Boletim do Laboratório Regional de Diagnóstico no.14, Pelotas. 97p.

Tanwar R.K., Malik K.S. \& Sadana J.R. 1993. Polioencephalomalacia induced with amprolio in buffalo calves: pathologic changes of the central nervous system. J. Vet. Med. 40:58-66

Weiblen R., Barros L.C.S., Canabarro T.F. \& Flores I.E. 1989. Bovine meningoencephalitis from IBR virus. Vet. Rec. 24:666-667. 